\title{
Correspondence
}

\section{Psychotherapy and Placebo}

SiR: Dr Mowbray (Journal, March 1986, 148, 337-338), suggests that "since the effects of placebo are psychological and the treatment in question (psychotherapy) is also "psychological" then we are simply comparing like with like-psychological with psychological". I think Dr Mowbray fails completely to understand the point I was trying to make in stating that placebo treatment was as successful as psychoanalysis or psychotherapy in general (but less so than behaviour therapy) in the treatment of neurotic patients.

The claims which have been, and are still being made for the various types of psychoanalytic and psychotherapeutic treatment are based on the theory that the treatments are in some way "specific" i.e., are derived from a more general theory of neurosis, and therefore are superior to other treatments not so derived, or derived from some alternative or inferior theory. This view was most clearly expressed by Freud, with respect to psychoanalysis, but it is equally held by the many other authors who favour alternative therapies.

The demonstration that placebo treatment which is by definition not only not derived from any specific theory, but expressly is defined in such a way as to exclude such specific influences as inform the therapy with which it is being compared, is equally successful in curing or ameliorating the disorders of neurotic patients clearly disproves any such claims for "specificity". Furthermore, if placebo treatment is as effective as psychoanalysis and psychotherapy in general, then why bother to spend years training psychoanalysts and psychotherapists, when this training clearly adds nothing to their efficacy? Indeed, Smith, Glass and Miller (1980), in a book often cited as proving the value of psychotherapy, found that duration of training of the therapist correlated zero with the efficacy of the treatment!

The only treatment which emerged as clearly superior in the varied comparative studies that have been done is behaviour therapy, suggesting that it alone has a specific effect which is related to the theory on which it is based (Eysenck, 1959). It is no doubt for this reason that behaviour therapy is being used more and more widely in the treatment of neurotic disorders.

Institute of Psychiatry

H. J. EYSENCK

De Crespigny Park

Denmark Hill, London SE5

References

EYSENCK, H. J. (1959) Learning theory and behaviour therapy. Journal of Mental Science, 105, 61-75.

Smith, M. L., Glass, G. V. \& MiLler, T. I. (1980) The Benefits of Psychotherapy. Baltimore: Johns Hopkins Press.

\section{Anniversary Reactions}

SIR: Renvoize \& Jain's Brief Report (Journal, March $1986,148,322-4)$ perpetuates a confusion which I (1981) tried to correct. An anniversary reaction should strictly speaking be the onset, or intensification, of symptoms at or about the anniversary of a significant past event, which was probably (though not necessarily) stressful. Such a reaction can occur each time the anniversary comes round, though it is likely to be most intense on the first anniversary. It has much in common with a delayed grief reaction and may well represent the expression of emotion which had been held back at the time of the original event.

Most of the examples presented by Renvoize \& Jain are what, more correctly, should be described as age-correspondence-precipitated reactions. These occur when the subject, or a close relative of the subject, reaches an age which corresponds with a time when a specific tragedy occurred to another person. This most likely represents a degree of identification with this other person, and is either a fear that the same tragedy will befall the subject, or an enactment, by the subject, in fantasy or reality, of the original tragedy. The distinguishing feature of the age-correspondence-precipitated reaction is that it can occur only once, namely when the two ages correspond.

Renvoize \& Jain maintain, though with no supportive evidence, that anniversary reactions are "probably quite common". True anniversary reactions, such as occur to widows or widowers one year 
after their partners' death (Bornstein \& Clayton, 1972) probably are common, though are mostly so mild as not to require the attention of psychiatrists. My own study suggests that age-correspondenceprecipitated reactions are rare. When they do occur it is important that they be recognised as such, since they can sometimes present as florid psychotic states (Hilgard \& Newman, 1959). I would be interested to know if any readers have experience of one.

MRC Social Psychiatry Unit
Institute of Psychiatry
De Crespigny Park
London SES 8AF
JOHN BIRTCHNELL

\section{References}

BiRTCHNELL, J. (1981) In search of correspondences between age a psychiatric breakdown and parental age at death-"anniversary reactions". British Journal of Medical Psychology, 54, III-120.

Bornsten, P. E. \& Clayton, P. J. (1972) The anniversary reaction. Diseases of the Nervous System, 33, 470-472.

Hulgard, J. R. \& Newman, M. F. (1959) Anniversaries in mental illness. Psychiatry, 22, 113-121.

\section{Depression and Urinary Free Cortisol}

SiR: B. J. Carroll (Journal, February 1986, 148, 218) questions the use of the radio-immuno assay (RIA) procedure and suggests that the urinary free cortisol (UFC) levels were unusually high in the patients in our study (Journal, October 1985, 147, 429-433). He states that the values were "all well within the range expected for patients with Cushing's Disease".

In fact, only 38 of the 72 patients had a 24 hour UFC secretion above the normal range (25-130 $\mu \mathrm{mg} / 24$ hours). The mean pre-dexamethasone 24-hour UFC was $158.6 \mu \mathrm{gm} / 24$ hours $(\mathrm{SD}=77.8$, range $33-378)$ which was higher than that found by Diegbold et al (1981) (mean $=122 \mu \mathrm{gm} / 24$ hours). One likely explanation for this is the fact that the patients in our study were essentially drug free in comparison to the above study and that of Carroll et al (1976) in which patients were treated with psychotropic medication, including benzodiazepines, which have been shown to lower cortisol levels.

The NIMH study (Stokes et al, 1984) on drug-free patients reported mean pre-dexamethasone UFC levels of $148 \mu \mathrm{mg} / 24$ hours in unipolar depressed patients, a result very similar to our own. Moreover, the post-dexamethasone UFC results in the two studies were remarkably similar with the NIMH study reporting levels of $59 \mu \mathrm{gms}$ per 24 hours, (and $65 \mu \mathrm{gm}$ per 24 hours in patients with unipolar depression), as compared to $65.4 \mu \mathrm{gm}$ per 24 hours in our study of mainly unipolar depressed patients (Calloway et al, 1984).

Carroll also questions the validity of using RIA for measuring plasma cortisols in the DST. It has been established that RIA gives comparable results to competitive protein binding (Wilens et al, 1983) and RIA is now the most widely used method for assaying cortisols in DST studies of depressed patients (e.g., Stokes et al, 1984).

Fulbourn Hospital, Cambridge CBI SEF

S. P. Calloway

Maudsley Hospital, London

R. J. DOLAN

\section{References}

Calloway, S. P., Dolan, R. J., Fonagy, P., De Souza, F. V. A \& WAKELNG, A. (1984) Endocrine changes and clinical profiles in depression. Psychological Medicine, 14, 749-65.

Carroll, B. J., Curtis, G. C., Davies, B. M., Mendels, J. \& Sugerman, A. A. (1976). Urinary free cortisol excretion in depression. Psychological Medicine, 6, 43-50.

Diebold, K., KICK, H. \& SChMDT, G. (1981) Urinary free cortisol excretion in endogenously depressed and schizophrenic patients. Psychiatria Clinica (Basel), 14, 43-48.

Stokes, P. E., Stoll, P. M., Koslow, S. H., MaAs, J. W., Davis, J. M., SwanN, A. C. \& Robrns, E. (1984) Pretreatment DST and hypothalmic-pituitary-adrenocortical function in depressed patients and comparison groups. A multicenter study. Archives of General Psychiatry, 41, 257-267.

Wilens, T. E., Arana, G. W., Baldessarnn, R. J. \& Cremens, C. (1983) Comparison of solid-phase radjoimmunoassay and competitive protein binding method for postdexamethasone cortisol levels in psychiatric patients. Psychiatry Research, 8, 199-206.

\section{Pseudodementia: Facts and Figures}

SIR: The article by Drs Bulbena and Berrios (Journal, January 1986, 148, 87-94) referred to the fact that speculation abounds in relation to the concept of pseudodementia. We decided to examine their observation "that there is no consensus on the use and application of the diagnosis of "pseudodementia". We will avoid commenting on how one diagnoses a presentation. We were also interested in seeing how closely our findings approached their "stringent criteria"- cognitive impairment of the dementia-type, absence of a relevant organic disorder, and reversibility.

We sent questionnaires, a covering letter, and s.a.e's. to a random sample of Irish psychiatrists of senior status $(n=65)$. We placed a five week deadline for the return of correspondence. Twenty-nine questionnaires were returned.

The questionnaire consisted of three questions. The answers given to these, including only those given by more than one respondent (absolute numbers in brackets) were as follows: 